\title{
Potential Application Techniques for Antimicrobial Textile Finishes
}

\author{
Muhammad Naveed* \\ Department of Applied Chemistry, Government College University Faisalabad, Pakistan
}

*Corresponding author: Muhammad Naveed, Department of Applied Chemistry, Government College University Faisalabad, Allama Iqbal Road38000, Pakistan

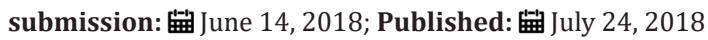

\begin{abstract}
The usage of antimicrobial textile products is aims to prevent microbial contamination and improving environmental hygiene. Antimicrobial agents are applied to textiles fabric that inhibit and kill the microbes when they become in contact with finished surface. Antimicrobial textiles are being utilizing continuously hygienically, where textiles surface is anticipated to contact with microbes. Owing to vastly diverse applications of antimicrobial textile products and intended usages, significant progress in developing novel application methods of antimicrobial agents has been accomplished in recent years. The efficacy of antimicrobial property also majorly depends application method beside nature and concentration of antimicrobial agent. Various antimicrobial agents require different application method on to textiles where they can maximum antimicrobial action. This article critically summarizes the potential applications techniques for finishing textiles with antimicrobial agents.
\end{abstract}

Keywords: Antimicrobial finishes; Application techniques; Testing; Performances

\section{Introduction}

Human beings always have learned to make textile products for their use by processing raw materials, dyeing, and finishing processes. Now in recent decades, both natural and synthetic fibers specially functionalized for smart applications are of the great importance for textile researchers to develop functional textiles. Such functional textiles can perform particular function for which these textiles are design, for example, anti-microbial, superhydrophobicity, UV protection, flame retardency, anti-smug, etc. Among these properties, capability to inhibit and kill the microbes is quite important for technical clothes. Textile products finished with antimicrobial functionalities are capable to resist and kill infectious microbes such as viruses, bacteria, fungi, spores etc. The synthesis and development of application methods of novel antimicrobial agents on to textile fabric has gained researchers interest owing to increased trend of continuous consumption of antimicrobial finished textiles. The potential antimicrobial agents have critically discussed in my previous article [1]. This study summarizes the efficient application methods for antimicrobial textile finishes.

\section{Pre and post application testing}

Various testing methods are employed before and after application of antimicrobial finishing to evaluate the antimicrobial functionalities. Such testing methods are as follows a) Safety testing of antimicrobial agent

b) Efficiency testing of antimicrobial agent

c) Durability testing after application

d) Resistance risks

Human skin must directly have exposed with antimicrobial textiles during usage, so it should be assured that finished textile will not irritate or harm the human skin. There must evidence that human skin is safe during use of antimicrobial textiles as antimicrobial agents do attack to bacterial cells and they will not harm the human skins cells. Several biological skin safety testing methods are available, such as DIN EN ISO 10993-5 (test for in vitro cytotoxicity), DIN EN ISO 10993-10 (skin irritation). Various microorganisms are populated in human skin which protect it and are collectively called as resident skin flora. The examples are propionic bacteria, yeasts, micrococci, coryneform bacteria and staphylococci. Pathogens infect and harm the humans when a disturbance of skin flora occur. The testing of antimicrobial agent for influence of resident skin flora is so necessary because finished agents cannot differentiate between beneficial microbes and infectious pathogens and thus they may damage resident skin flora too. An artificial skin model cultured with Staphylococcus epidermidis and Micrococcus luteus is used for testing resident skin flora in laboratory method. 
The finished textile products should exhibit validated antimicrobial effect regarding registration, marketing and customer satisfaction. Various standardized methods are available to test effectiveness of antimicrobial textiles including qualitative and quantitative evaluation with different experiment setups. The most important methods are mentioned below.

Antifungal assessment

a) Quantitative evaluation (DIN 14119)

b) Semi quantitative evaluation (AATCC 30)

Antibacterial assessment

c) Shake flask test (ASTM E2149)

d) Agar plate diffusion test (DIN EN ISO 20645)

e) Parallel streak method (AATCC 147)

f) Quantitative Evaluation (AATCC 100)

g) Quantitative Evaluation (DIN EN ISO 20743)

Durability testing is another important evaluation regarding antimicrobial textiles products, as the antimicrobial efficacy should be continual for a long period preferably lifetime of finished product. However, the nature, concentration, consumption, stability and method of application of antimicrobial agent do greatly affect the durability of antimicrobial finished textiles [2,3]. Degradation, consumption reduce the concentration of agent and ultimately affect the effectiveness. The durability is evaluated in laboratory from many washing cycles and storage times while antimicrobial efficiency is to test before and after durability tests. A slight decrease in antimicrobial activity reflects high durability of finished textile while a low durability is revealed from significant decrease in antimicrobial activity.

Commonly, 50 washing cycles are employed to check remaining antimicrobial activity for durability testing. Various standard washing test methods are DIN EN ISO 6330 and Din EN ISO 15797. The most test conditions for storage stability are 75\% humidity; 40 ${ }^{\circ} \mathrm{C}$; 3-9 months (accelerated aging) and $60 \%$ humidity; $25{ }^{\circ} \mathrm{C} ; 12-36$ months (real time aging). Pathogens may resist against the effect of antimicrobial agent by developing diverse resistance mechanism to destroy or neutralize the effect of agents. Thus, resistance risks should be precisely addressing to get maximum antibacterial performance of finished textiles product.

\section{Application Methods}

A few application method for antimicrobial finishing of textile fabric have been reported and are under development to be implement on large scale depend upon particular fiber type and antimicrobial agent. As for as natural fiber is concerned, the most commonly used method to finish surface with antimicrobial agent either binding antimicrobial agent covalently or other type of electrostatic interactions with fiber. Such antimicrobial finish may remain on surface of fiber or undergo leaching mechanism depending upon the interaction between agent and fiber. An extra advantage may utilize for imparting antimicrobial functionality to synthetic fiber where the active agent can be blend in precursor polymer prior to its extrusion for fiber formation. As the active agent become physically embedded in polymeric microstructure of fiber which leaches slowly with usage and thus provide best durability. Trevira is the best example containing silver-based antimicrobial agent embedded in polyester. Such advantage may also avail from semi-synthetic fiber such as regenerated cellulose fibers doped with silver-based antimicrobials prior to spinning process [4-9].

Surface finishing of fabric with antimicrobial agent is commonly employ by using pad-dry-cure, conventional exhaustion, padding, spraying or foam finishing for both synthetic as well as natural fibers. Other methods are polymer grafting of active agent during polymerization, crosslinking of active agent on to fiber surface via a suitable cross-linker, chemical modification of active agent for binding with fiber covalently, nano-scale core-shell particles, nanoscale colloidal solutions or hydrosols [10]. Among them potentially, antimicrobials are microencapsulated via emulsion polymerization or entrapping them in suitable sol-gel nanoparticles and applied to both natural and synthetic fibers [11-25].

Whatever the method is chosen for antimicrobial finishing, several requirements should meet by applied antimicrobial finish to accomplish optimal performance during its service time. A good antimicrobial finish should exhibit following major requirements.

a) Should not be toxic, irritating or allergic to human body

b) Should not affect or kill the resident skin flora

c) Should meet standards regarding compatibility test, e.g., sensitization, irritation, cytotoxicity

d) Should be compliance with government regulations

e) Should be efficient for a wide range of microorganisms

f) Should not affect adversely with quality of fabric, e.g., comfort, handling or strength

g) Should be compatible with other textile processes during textile treatments

h) Should be durable to laundering even after several wash cycles, drying or hot pressing

i) Should be durable to storage for long time

j) Should be eco-friendly and cost effective

\section{Sol-gel technology}

Sol-gel method is one of the most effective and simplest methods for developing various nanocomposites among all other fabricating techniques of nano-coatings. Antimicrobial agents applied to fabric via sol-gel method offer maximum antimicrobial power and durability of applied agent. Inorganic matrices (e.g., silica) act as supporting hosts for antimicrobial agent. The entrapment of biocidal agent with inorganic matrix depends upon extent of control on various stages of sol-gel processes. Advantageously, 
these antimicrobial functionalized sol-gels can perfectly deposit on surface of fabric via electrospinning, spray coating, spin coating, dip coating, and pad dry curing methods. Most widely used application method of sol-gel is pad dry curing.

Sol-gel method is a technique for fabrication of variety of inorganic or hybrid inorganic-organic networks resulting in porous, glass or ceramics like material from sol-gel reactions of metal alkoxide precursors. Colloidal suspensions of solid particles in solvent called sol while gel exhibit solid phase framework surrounds a continuous liquid phase. Advantageously, room temperature is requiring for sol-gel reactions as gel cures at moderate temperature. Such simplicity and versatility in sol-gel method make it suitable for film formation with functional properties.

Hydrolysis, condensation, and polycondensation are fundamental reactions, which occur during sol-gel process. Figure $1 \& 2$ depicts principle steps of sol-gel process. Silicon alkoxides are most widely used alkoxides, e.g., tetramethoxy silane (TEOS) and teramethoxy silane (TMOS) but other metal alkoxide also follow similar reaction mechanism (i.e., zirconates, titanates, aluminates) [26-28].

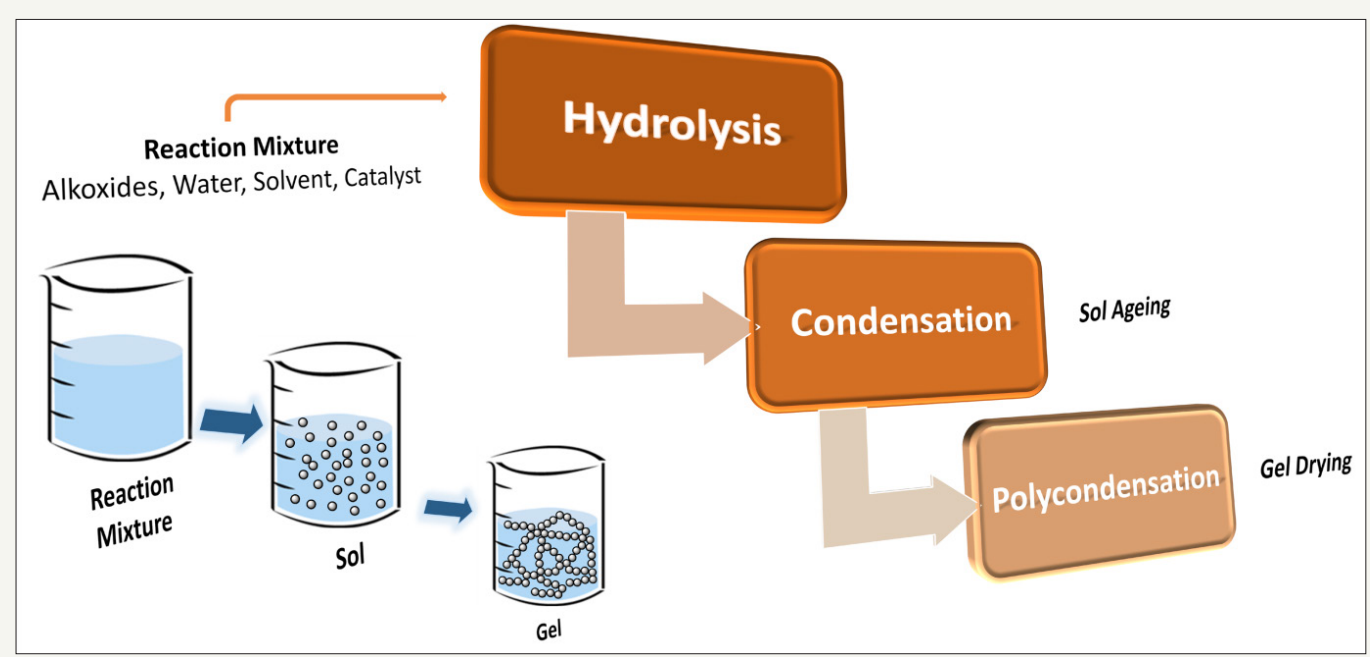

Figure 1: Three stages of sol gel process.

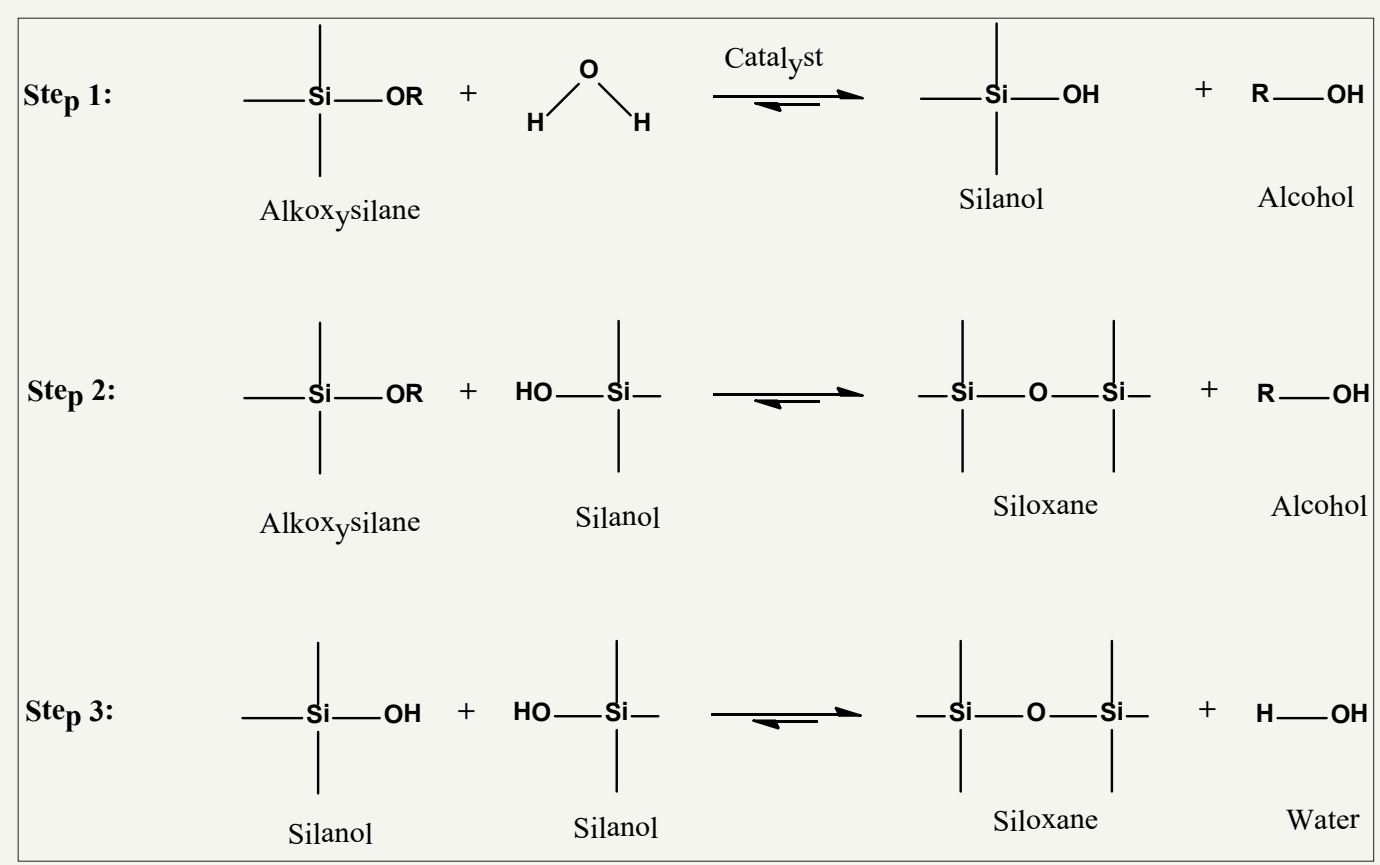

Figure 2: Three reaction schemes involving in sol-gel process.

Incorporation of water in silane solution under basic, neutral or acidic conditions results in hydrolysis process (Figure 3). Corresponding alcohol and Hydroxylated (silanol group) products are produced as the results of hydrolysis of silicon alkoxide precursors (Step 1). Hydroxyl group and unhydroxylated alkoxide group undergoes condensation reaction that results in appearance 
of colloidal mixture (sol) with elimination of solvent. Formation of three-dimensional crosslinking between sols as a result of polycondensation reaction increased the viscosity of solution gradually. The resultant product is called gel that is relatively porous and rigid produce from interconnecting sols. Various parameters of sol-gel process like nature and concentration of precursors, temperature and water to silane ratio, sol aging time and nature of catalyst do affect the properties of final gel formation. Both base and acid catalyzed gels forms structures with varying degree of crosslinks. Linear structure is formed from acid catalyzed reaction while crosslinked structure is formed from base catalyzed reaction (Figure 3).

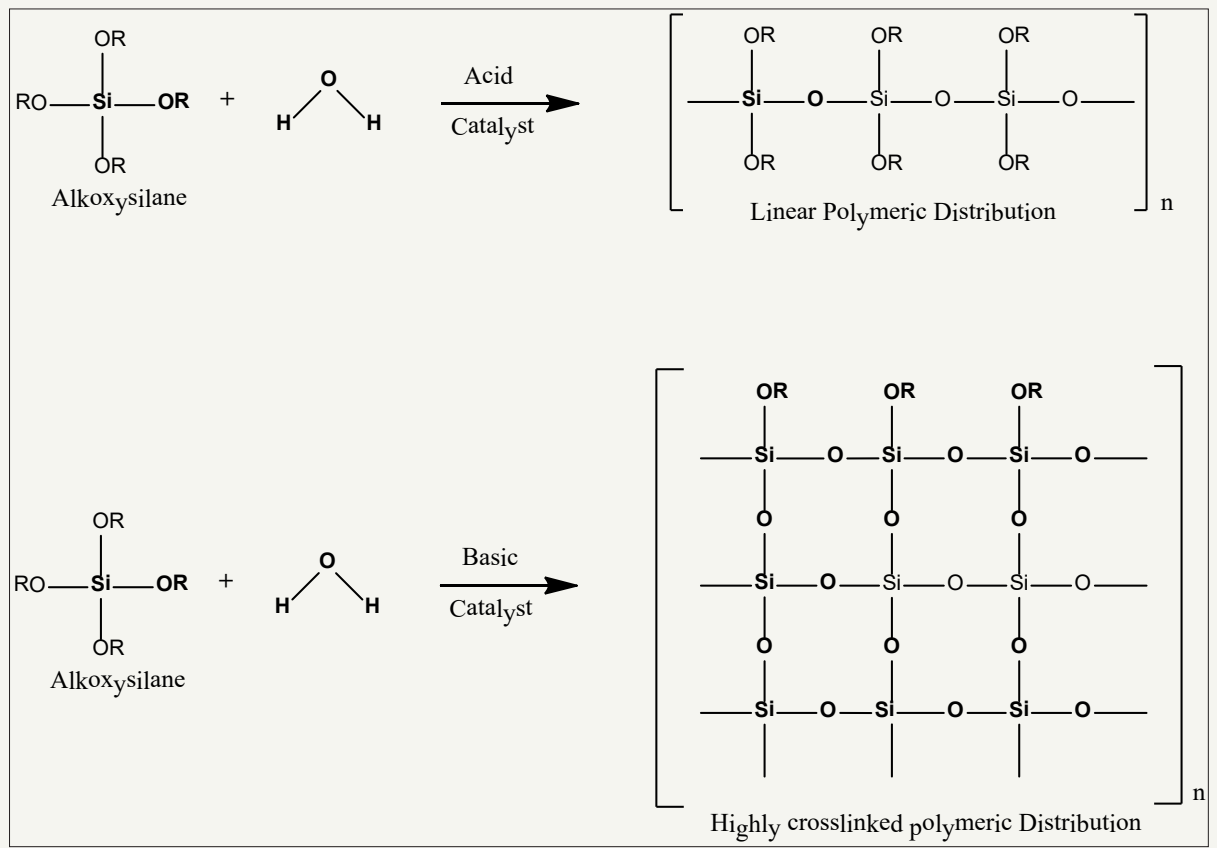

Figure 3: Polymeric distribution of the resultant gel as a function of acid or basic catalysis.

Use of nanoparticles has gained much popularity in recent decades owing to their decreased size and high surface to volume ratio that makes their surface highly active. One of the efficient methods to apply antimicrobial agent on textile fabric is to entrap them in different metal/metal oxide sol-gel matrices. This method has shown good efficacy and durability even after several washes. Examples are ionic silver or silver-based compounds in silica matrix [11,29-37], Zin based [17,22,23,38-40] and Titanium based [41-43].

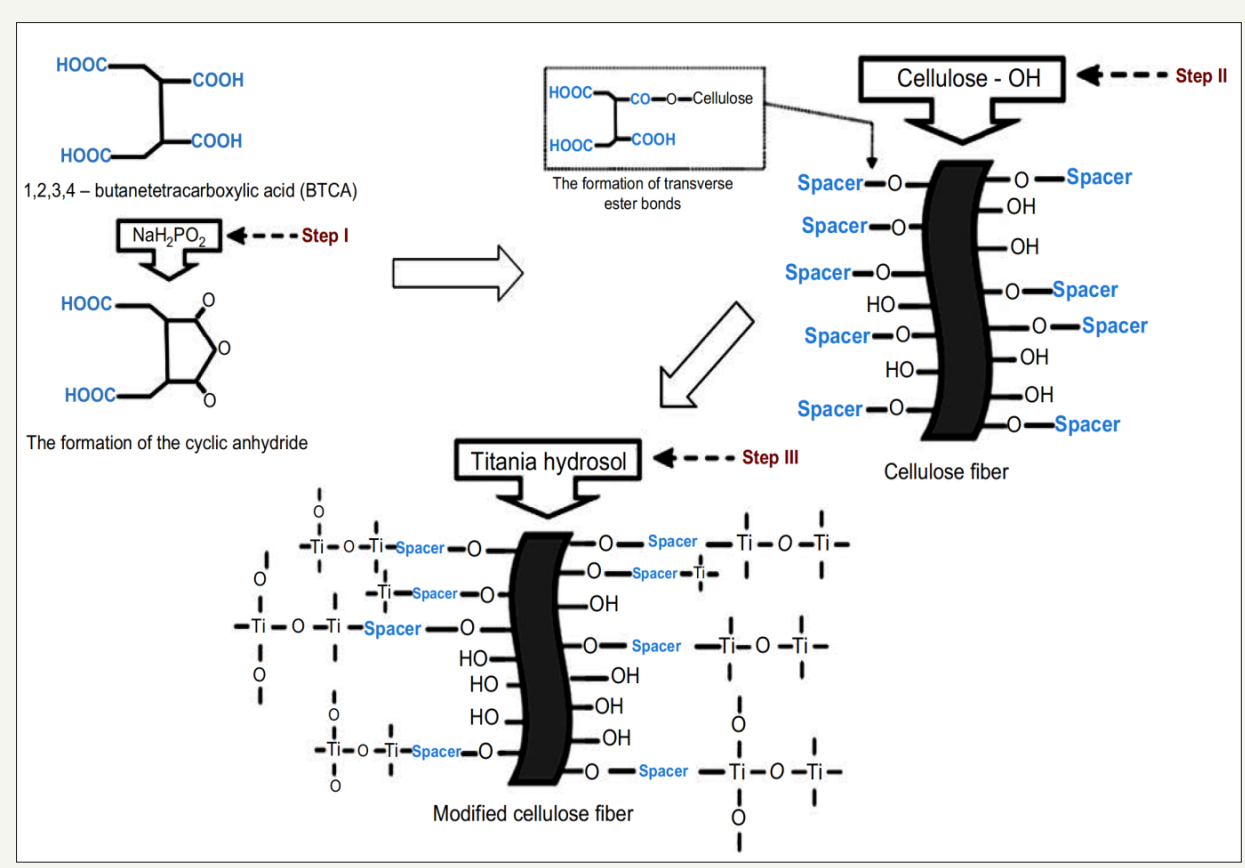

Figure 4: The mechanism of interaction of cotton fibers with TiO2, BTCA [35]. 

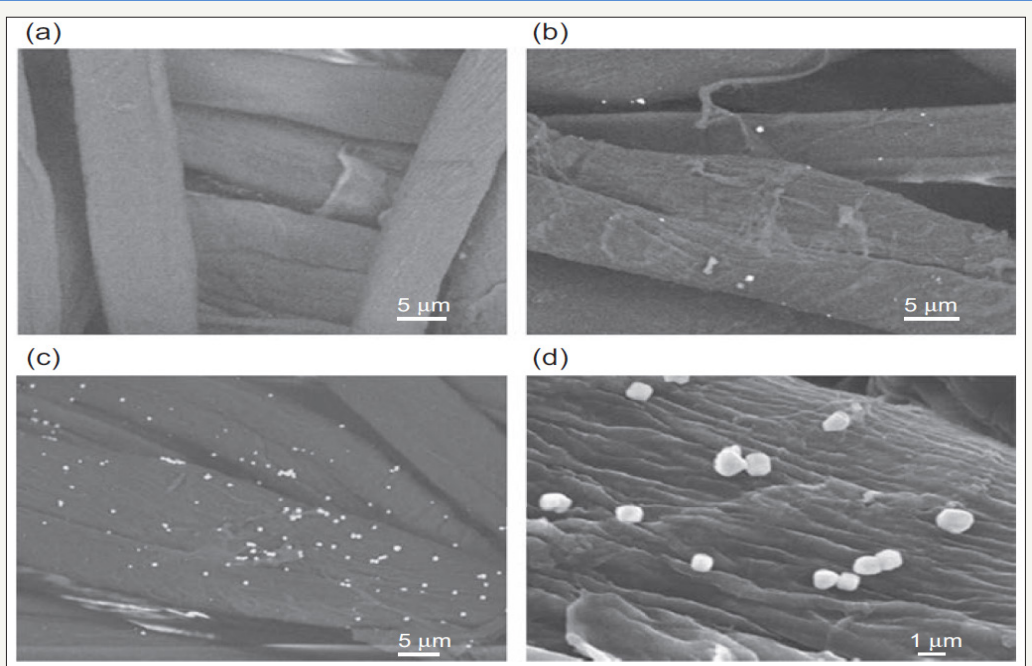

Figure 5: SEM images of (a) unfinished cotton fabric, (b) unwashed cotton fabric fabricated by pad-dry-cure method, (c) unwashed cotton fabric fabricated by exhaustion method and (d) Zoom-in of image (c) [35].

Furthermore, interactions between fiber surface and incorporated hydrosol containing antimicrobial agent can be efficiently tailor by a suitable cross-linker that persist the binding of agent on to fiber, e.g., attachment of titania hydrosol on to cellulose fiber via crosslinking of 1,2,3,4-butancetetracarboxylic acid (BTCA) Figure 4 \& 5; [44].

\section{Microencapsulation}

Microencapsulation is a rapidly growing method that have used for diverse applications specially in textile industry [24,25,45-50]. This process involves the formation of microencapsules having two parts core and shell. Figure 5 depicts the schematic view of coreshell microcapsule. Core contains the active agents which are very tiny particles of solid or droplets of liquid coated or sorrounded by continous film of polymeric material forming the shell as the whole. So, core is the interal phase contains active agents while shell is exteral phase which is the membrane, coating or wall material. Actually, microencapsulation provide the storing, seperating and pasaging of active materials at microscopic level. Microencapsules release the active agents gradually under the condition that have programmmed for that particular microencapsules and achieve the particular performance. Amount of core-material and thichness of wall material decides the mechanism of release of active agents. The possible mechanisms that may involve the release of acitve agents from microencapsule are bursting of shell, biodegradation, dissolution of polymeric wall material, diffusion through wal, change in temperature or pressure, by friction, etc. A number of advantages that make microencapsulation technique prime to others mehtods of apllications for antimcirobial finishing are as follows.

a) Convenient in handling of a large number of antimicrobial agents

b) Improved flowability, dispersibility and solubility is achieve for better processing

c) Improved availability and compatibility is gain for antimicrobial finishing

d) Shelf-life is impoved as some degradation side reactions are avoided

e) Sustainded and controlled release of antimicrobial agent

f) Antimicrbial agents become stable for long period of time from external environments (evaporation, moisture, alkanility, acidity, heat etc) prior to use of finished fabric

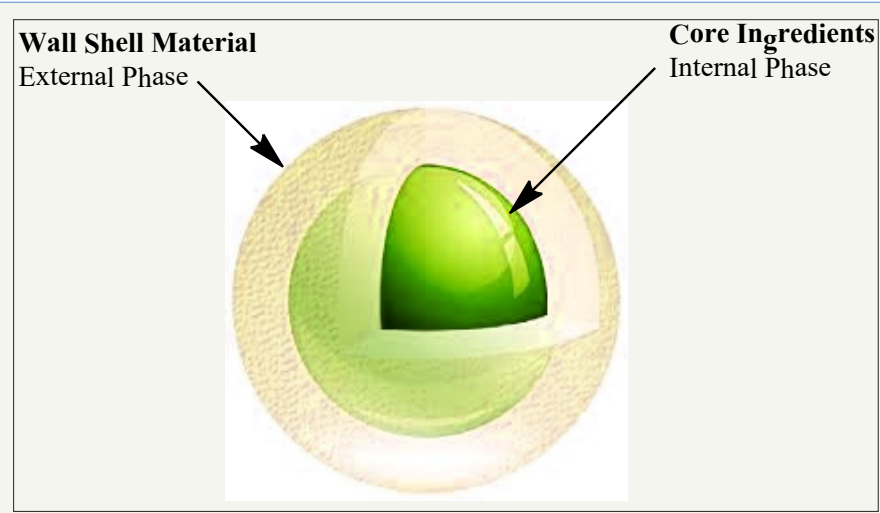

Figure 6: Schematic of Core-Shell diagram of microcapsule. 
Chitosan is a well studies antimicrobial agent [51-57]. The schematic view of preparation of chitosan microencapsulation is depicted in Figure 6. The effective conditions or parameters that affect the yield of microcapsules are;

a) Controlled release behavior, surface morphology and particle size of microcapsules depend upon mass ration of core ingredients and shell material

b) Speed of agitation prior to crosslinking reaction

c) Yield of microcapsules is proportional to the shell material concentration d) Surface adhesion and shell strength of microcapsules are influence directly by crosslinking time

(Figure 7); [58] Controlled release of antimicrobial agents for a prolong durability even against daily use and after several wash cycles, is achieved by microencapsulation technology. For water in oil or oil in water medium, cocreation is a mature microencapsulation method [59-62]. Encapsulation of natural biocides through this technique is becoming popular in these days performing as multifunctional finishes that not only provides antibacterial functionalities but also serves as a fragrance.
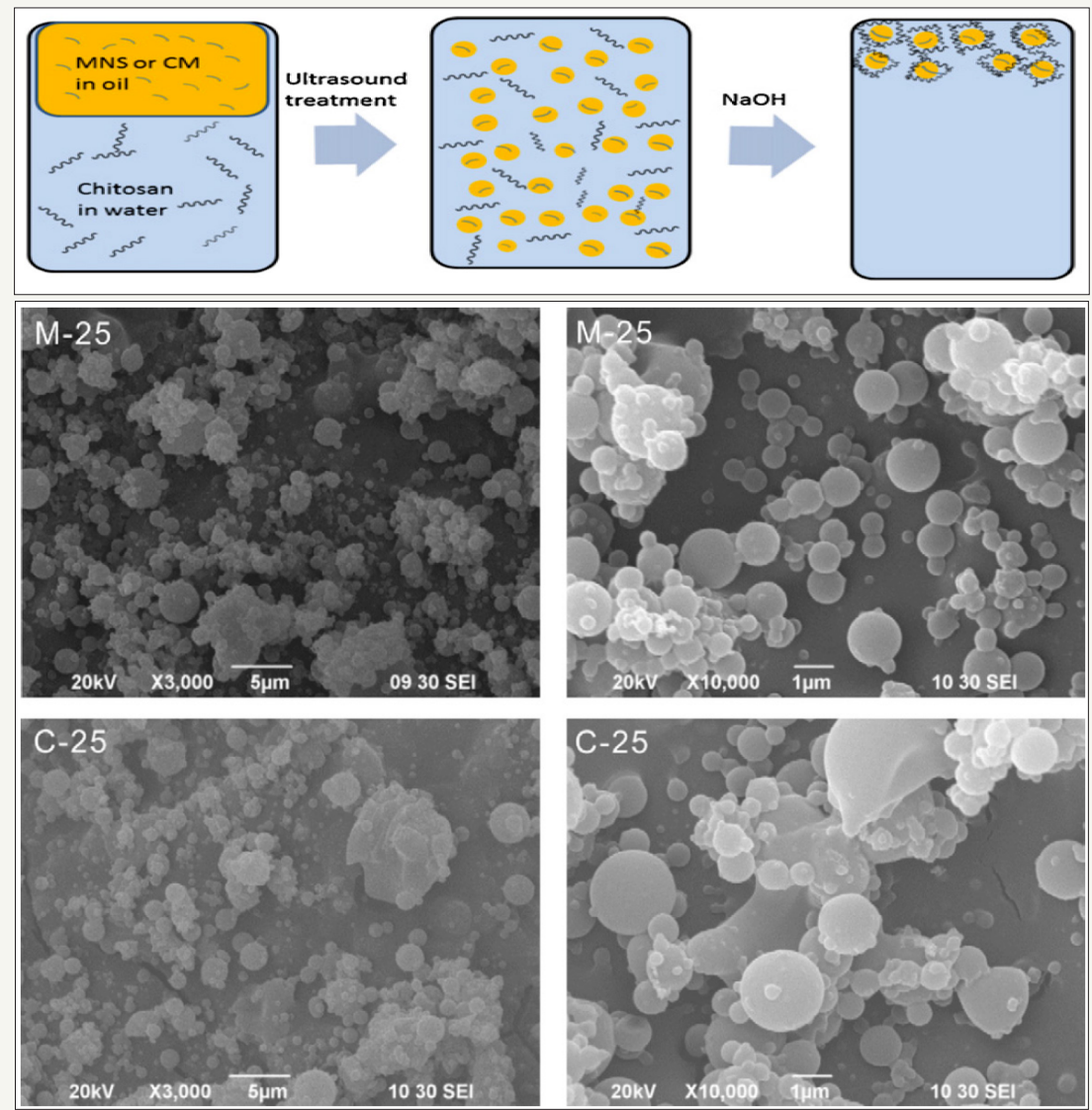

Figure 7: Schematic diagram and SEM images of the chitosan/miconazole nitrate prepared from microencapsulation method [58].

\section{Conclusion}

Antimicrobial agents inhibit the growth of infectious microbes and kill them whenever microbes become in contact with them. These antimicrobial agents are being extensively applied to textile fabrics in order to use them hygiene purposes regarding human health issures such as, inhibiting microbes from spreading, control of infections, control of odor, healing of wound, etc. Various application methods of antimicbial agents on to textile farbric surface have developed. The selection of suitable applicatin method depends upon a number of parameters like nature and concentration of antimicrbial agent, type of textile fabric, etc. Microencapsulation and sol-gel methods are convinient and efficient methods that provid excellent efficacy and durability to antimicrobial finished farbics. Advandegiously, these methods are also suitable for multifunctional finishing of fabrics that possess phase change, antistatic, anti smug, self healing properties.

\section{References}

1. Naveed M (2018) Performance on antibacterial finishes for textile applications. Trends Text Eng Fash Technol 2(5): 1-10.

2. Lorenz C, Windler L, von Goetz N, Lehmann RP, Schuppler M, et al. (2012) Characterization of silver release from commercially available functional (nano) textiles. Chemosphere 89(7): 817-824.

3. Ranganath AS, Sarkar AK (2014) Evaluation of durability to laundering of triclosan and chitosan on a textile substrate. J Text 2014: 1-5.

4. Chen JY, Sun L, Jiang W, Lynch VM (2015) Antimicrobial regenerated cellulose/nano-silver fiber without leaching. J Bioact Compat Polym 30(1): 17-33. 
5. Shankar S, Oun AA, Rhim JW (2018) Preparation of antimicrobial hybrid nano-materials using regenerated cellulose and metallic nanoparticles. Int J Biol Macromol (107): 17-27.

6. Kalwar K, Hu L, Li DL, Shan D (2018) AgNPs incorporated on deacetylated electrospun cellulose nanofibers and their effect on the antimicrobial activity. Polym Adv Technol 29(1): 394-400.

7. Cao C, Wu K, Yuan W, Zhang Y, Wang H (2017) Synthesis of non-water soluble polymeric guanidine derivatives and application in preparation of antimicrobial regenerated cellulose. Fibers Polym 18(6): 1040-1047.

8. Shao W, Wang S, Wu J, Huang M, Liu H, et al. (2016) Synthesis and antimicrobial activity of copper nanoparticle loaded regenerated bacterial cellulose membranes. RSC Adv 6(70): 65879-65884.

9. Chowdhury NA, Al-Jumaily AM (2016) Regenerated cellulose/ polypyrrole/silver nanoparticles/ionic liquid composite films for potential wound healing applications. Wound Med14: 16-18.

10. Gao Y, Cranston R (2008) Recent advances in antimicrobial treatments of textiles. Text Res J 78(1): 60-72.

11. Mahltig B, Fiedler D, Simon P (2011) Silver-containing sol-gel coatings on textiles: Antimicrobial effect as a function of curing treatment. J Text Inst 102(9): 739-745.

12. Pakdel E, Daoud WA, Wang X (2015) Assimilating the photo-induced functions of $\mathrm{TiO}_{2}$-based compounds in textiles: Emphasis on the sol-gel process. Text Res J 85(13): 1404-1428.

13. Farouk A, Moussa S, Ulbricht M, Schollmeyer E, Textor T (2014) ZnOmodified hybrid polymers as an antibacterial finish for textiles. Text Res J 84(1): 40-51.

14. Selvam S, Rajiv GR, Suresh J, Gowri S, Ravikumar S, et al. (2012) Antibacterial effect of novel synthesized sulfated $\beta$-cyclodextrin crosslinked cotton fabric and its improved antibacterial activities with $\mathrm{ZnO}, \mathrm{TiO}_{2}$ and Ag nanoparticles coating. Int J Pharm 434(1-2): 366-374.

15. Pisitsak P, Ruktanonchai U (2015) Preparation, characterization, and in vitro evaluation of antibacterial sol-gel coated cotton textiles with prolonged release of curcumin. Text Res J 85(9): 949-959.

16. Ismail WNW (2016) Sol-gel technology for innovative fabric finishing-A review. J Sol-Gel Sci Technol 78(3): 698-707.

17. Poli R, Colleoni C, Calvimontes A, Polášková H, Dutschk V, et al. (2015) Innovative sol-gel route in neutral hydroalcoholic condition to obtain antibacterial cotton finishing by zinc precursor. J Sol-Gel Sci Technol 74(1): 151-160.

18. El-Shafei A, ElShemy M, Abou-Okeil A (2015) Eco-friendly finishing agent for cotton fabrics to improve flame retardant and antibacterial properties. Carbohydr Polym 118: 83-90.

19. El-Naggar ME, Shaheen TI, Zaghloul S, El-Rafie MH, Hebeish A (2016) Antibacterial activities and UV protection of the in situ synthesized titanium oxide nanoparticles on cotton fabrics. Ind Eng Chem Res 55(10): 2661-2668.

20. Xu Y, Wen W, Wu JM (2018) Titania nanowires functionalized polyester fabrics with enhanced photocatalytic and antibacterial performances. J Hazard Mater 343: 285-297.

21. Kowalczyk D, Brzeziński S, Kamińska I (2015) Multifunctional bioactive and improving the performance durability nanocoatings for finishing PET/CO woven fabrics by the sol-gel method. J Alloys Compd 649: 387393.

22. Farouk A, Sharaf S, Shalaby A (2016) $\mathrm{ZnTiO}_{3}$ nanoparticles as novel multifunctional finishing of cotton fabric. Egypt J Chem 59(5): 819-830.

23. Água RBD (2018) Efficient coverage of $\mathrm{ZnO}$ nanoparticles on cotton fibres for antibacterial finishing using a rapid and low cost in situ synthesis. New J Chem 42(2): 1052-1060.
24.El-Rafie HM, El-Rafie MH, AbdElsalam HM, El-Sayed WA (2016) Antibacterial and anti-inflammatory finishing of cotton by microencapsulation using three marine organisms. Int J Biol Macromol 86: 59-64.

25. Hassan MM, Sunderland M (2015) Antimicrobial and insect-resist wool fabrics by coating with microencapsulated antimicrobial and insectresist agents. Prog Org coatings 85: 221-229.

26. Brinker CJ, Keefer KD, Schaefer DW, Ashley CS (1982) Sol-gel transitions in simple silicates. J Non Cryst Solids 48(1): 47-64.

27. Brinker CJ, Keefer KD, Schaefer DW, Assink RA, Ashley CS (1984) Sol-gel transition in simple silicates II. J Non Cryst Solids 63(1-2): 45-59.

28. Brinker CJ (1988) Hydrolysis and condensation of silicates: Effects on structure. J Non Cryst Solids 100(1-3): 31-50.

29. Timin A, Rumyantsev E (2013) Silver-silica nanocomposite materials incorporated into textile fabrics: Chemical and biological study. Bionanoscience 3(4): 415-422.

30. Jasiorski M (2009) Textile with silver silica spheres: Its antimicrobial activity against Escherichia coli and Staphylococcus aureus. Journal of Sol-Gel Science and Technology 51(3): 330-334.

31. Shin YS, Park M, Kim HY, Jin FL, Park SJ (2014) Synthesis of silver-doped silica-complex nanoparticles for antibacterial materials. Bull Korean Chem Soc 35(10): 2979-2984.

32. Wu CS, Liao HT (2011) Antibacterial activity and antistatic composites of polyester/Ag-SiO 2 prepared by a sol-gel method. J Appl Polym Sci 121(4): 2193-2201.

33. Nischala K, Rao TN, Hebalkar N (2011) Silica-silver core-shell particles for antibacterial textile application. Colloids Surfaces B Biointerfaces 82(1): 203-208

34. Tarimala S, Kothari N, Abidi N, Hequet E, Fralick J, et al. (2006) New approach to antibacterial treatment of cotton fabric with silver nanoparticle-doped silica using sol-gel process. J Appl Polym Sci 101(5): 2938-2943.

35. Tomšič B (2009) Antimicrobial activity of $\mathrm{AgCl}$ embedded in a silica matrix on cotton fabric. Carbohydr Polym 75(4): 618-626.

36. Catauro M, Raucci MG, De Gaetano F, Marotta A (2004) Antibacterial and bioactive silver-containing $\mathrm{Na}_{2} \mathrm{O} \cdot \mathrm{CaO} \cdot 2 \mathrm{SiO}_{2}$ glass prepared by sol-gel method. J Mater Sci Mater Med 15(7): 831-837.

37. Lkhagvajav N, Yasa I, Celik E, Koizhaiganova M, Sari O (2011) Antimicrobial activity of colloidal silver nanoparticles prepared by solgel method. Dig J Nanomater Biostruct 6(1): 149-154.

38. Dhineshbabu NR, Manivasakan P, Palaniswamy NK, Prabu P, Gobi N, et al. (2014) Development of functional hybrid cotton fabrics by coating with $\mathrm{SiO}_{2}$ and $\mathrm{ZrO} 2 / \mathrm{SiO}_{2}$ composites. Micro Nano Lett 9(10): 717-720.

39. Dong Y, Thomas NL, Lu X (2017) Electrospun dual-layer mats with covalently bonded $\mathrm{ZnO}$ nanoparticles for moisture wicking and antibacterial textiles. Mater Des 134: 54-63.

40. Buşilə M, Muşat V, Textor T, Mahltig B (2015) Synthesis and characterization of antimicrobial textile finishing based on Ag: $\mathrm{ZnO}$ nanoparticles/chitosan biocomposites. RSC Adv 5(28): 21562-21571.

41. Galkina OL (2014) The sol-gel synthesis of cotton/ $\mathrm{TiO}_{2}$ composites and their antibacterial properties. Surf Coatings Technol 253: 171-179.

42. Horkavcová D, (2017) Titania sol-gel coatings containing silver on newly developed TiSi alloys and their antibacterial effect. Mater Sci Eng C 76: 25-30.

43. Kaviyarasu K (2017) Photocatalytic performance and antimicrobial activities of $\mathrm{HAp}-\mathrm{TiO}_{2}$ nanocomposite thin films by sol-gel method. Surfaces and Interfaces 6: 247-255. 
44. Nelson G (2001) Microencapsulation in textile finishing. Color Technol 31(1): 57-64

45. Nelson G (2002) Application of microencapsulation in textiles. Int J Pharm 242(1-2): 55-62.

46. Katewaraphorn J, Aldred AK (2016) A study of microcapsules containing Psidium guajava leaf extract for antibacterial agent on cotton fabric. Int J Chem Eng Appl 7(1): 27.

47. Asadi F, Shakoorjavan S, Akbari S (2018) The relationship between odour intensity and antibacterial durability of encapsulated thyme essential oil by PPI dendrimer on cotton fabrics. J Text Inst 109(6): 832-841.

48. Salaün F (2016) Microencapsulation technology for smart textile coatings. Active Coatings for Smart Textiles, Elsevier, pp. 179-220.

49. Aziz FRA, Jai J, Raslan R, Subuki I (2015) Microencapsulation of essential oils application in textile: A review. Adv Mater Res 1113.

50. Moazeni N, Mohamad Z, Faisal NLI, Tehrani MA, Dehbari N (2013) Anticorrosion epoxy coating enriched with hybrid nanozinc dust and halloysite nanotubes. J Appl Polym Sci 130(2): 955-960.

51. Cremar L, Gutierrez J, Martinez J, Materon L, Gilkerson R, et al. (2018) Development of antimicrobial chitosan based nanofiber dressings for wound healing applications. Nanomedicine J 5(1): 6-14.

52. Amato A, Migneco LM, Martinelli A, Pietrelli L, Piozzi A, et al. (2018) Antimicrobial activity of catechol functionalized-chitosan versus Staphylococcus epidermidis. Carbohydr Polym 179: 273-281.

53. Pranantyo D, Xu LX, Kang ET, Chan-Park MB (2018) Chitosanbased peptidopolysaccharides as cationic antimicrobial agents and antibacterial coatings. Biomacromolecules 19(6): 2156-2165.

54. Xu Q Xie L, Diao H, Li F, Zhang Y, et al. (2017) Antibacterial cotton fabric with enhanced durability prepared using silver nanoparticles and carboxymethyl chitosan. Carbohydr Polym 177: 187-193.

55. Bhuiyan MAR, Hossain MA, Zakaria M, Islam MN, Uddin MZ (2017) Chitosan coated cotton fiber: physical and antimicrobial properties for apparel use. J Polym Environ 25(2): 334-342.

56. Scacchetti FAP, Pinto E, Soares GMB (2017) Preparation and characterization of cotton fabrics with antimicrobial properties through the application of chitosan/silver-zeolite film. Procedia Eng 200: 276282.

57.Xu Q (2018) Surface modification by carboxymethy chitosan via pad-dry-cure method for binding Ag NPs onto cotton fabric. Int J Biol Macromol 111: 796-803.

58. Yuen CWM (2012) Chitosan microcapsules loaded with either miconazole nitrate or clotrimazole, prepared via emulsion technique. Carbohydr Polym 89(3): 795-801.

59. Sharma R, Goel A (2018) Development of insect repellent finish by a simple coacervation microencapsulation technique. Int J Cloth Sci Technol 30(2): 152-158.

60. Liu J, Liu C, Liu Y, Chen M, Hu Y, et al. (2013) Study on the grafting of chitosan-gelatin microcapsules onto cotton fabrics and its antibacterial effect. Colloids Surfaces B Biointerfaces 109: 103-108.

61. Specos MM, Garcia JJ, Tornesello J, Marino P, Della Vecchia M, et al. (2010) Microencapsulated citronella oil for mosquito repellent finishing of cotton textiles. Trans R Soc Trop Med Hyg 104(10): 653-658.

62. Chatterjee S, Salaün F, Campagne C (2014) Development of multilayer microcapsules by a phase coacervation method based on ionic interactions for textile applications. Pharmaceutics 6(2): 281-297.
Creative Commons Attribution 4.0 International License

For possible submissions Click Here Submit Article

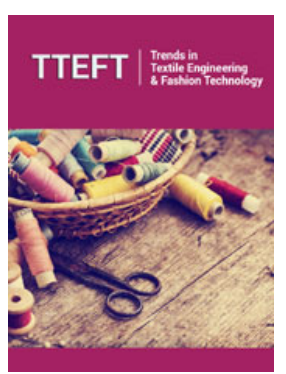

Trends in Textile Engineering \& Fashion Technology

\section{Benefits of Publishing with us}

- High-level peer review and editorial services

- Freely accessible online immediately upon publication

- Authors retain the copyright to their work

- Licensing it under a Creative Commons license

- Visibility through different online platforms 